\title{
W. H. R. Rivers's "An address on the repression of war experience"
}

\section{Peter Howorth}

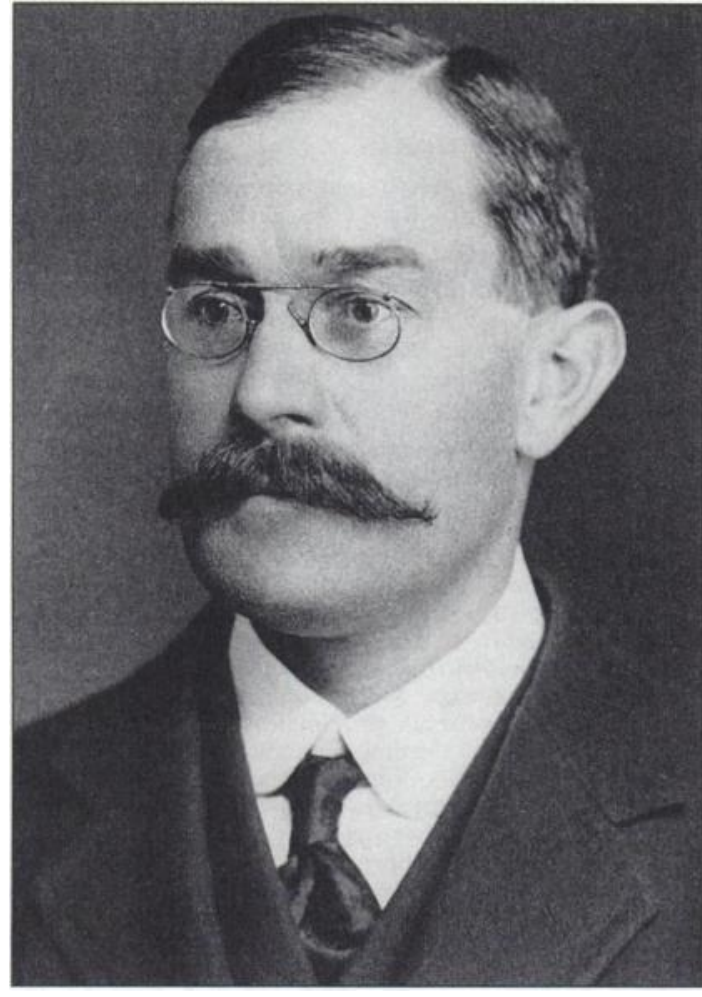

Fig. 1. W. H. R. Rivers

(C) The Royal Society, 1996

The award of the 1995 Booker prize to Pat Barker for The Ghost Road, the final part of her trlogy of novels about the First World War (the others being Regeneration and The Eye in the Door), brings due recognition to a fascinating reconstruction of the personal experiences of soldiers involved in that conflict. In its focus on the psychological effects of war, and on the central figure of Dr Rivers who treated many casualties at Craiglockhart Hospital near Edinburgh, the trilogy offers a slant on the war which is of considerable psychiatric interest.
W. H. R. Rtvers (1864-1922) gave an address to the Section of Psychiatry of the Royal Society of Medicine in December 1917 which was published in the Lancet (1918) two months later. It is a remarkable paper; reading it we follow the author on a journey of discovery as he refines and tests different hypotheses and therapeutic strategles. He outlines the mechanisms underlying battle neurosis, describes the treatment of four individual cases and discusses the factors involved in successful therapy.

Rivers terms the process whereby experiences in the trenches develop into anxiety, disturbed sleep and terrifying nightmares, 'repression'. He gives a commonsense explanation of this as "the attempt to banish from the mind distressing memories of warfare or painful affective states which have come into being as a result of their war experience". As such it appears to be closer to the concept of 'avoidance', a central feature of post-traumatic stress disorder (PTSD), than to repression as an unconscious mechanism. His view is that the effort to banish distressing memories from awareness, often encouraged by advice from others to "forget all about it", is doomed to failure. Instead the traumatic experiences must be brought to light in order to make sense of them, or they will continue to haunt the sufferer.

Rivers's case descriptions show him to have been an intuittve, sensittve therapist, able to adapt his theories to each patient in a pragmatic way. The techniques he describes are closer to what would now be classed as 'cognittve' approaches than to conventional psychotherapy.

In the first case, that of a young man who has nightmares about the war, and is nervous and hypervigilant, Rtvers employs a form of cognitive restructuring. He suggests to the soldier that, rather than trying to banish his memories from his mind, "he should see whether it was not possible to make them into tolerable, if not even pleasant, companions, instead of evil influences which forced themselves upon his mind". Patient and therapist collaborate in a 'behavioural experiment', and the intrustve thoughts of warfare reduce in intensity, sleep improves, and the soldier is able to return to duty.

The reframing of experience in order to make sense of it is also described in the next case, that 
of an officer buried after a shell explosion and shortly afterwards assigned the duty of collecting the separated head and limbs of a fellow officer blown to pieces by a shell. He became haunted by visions and nightmares of his mutllated friend. Rivers states that: "The problem before me in this case was to find some aspect of the painful experience which would allow the patient to dwell upon it in such a way as to relieve its horrible and terrifying character". His solution is to emphasise that his friend had been killed outright, and thus spared prolonged suffering from a mortal wound. This approach enables the officer to come to terms with his experiences, and there is a moving description of a dream in which he finds his friend in No Man's Land and saves his personal effects for his relatives - a dream from which he awakes "with none of the horror of the past, but weeping gently, feeling only grief for the loss of a friend".

Rtvers then describes two cases with a less successful outcome. The first will be familiar to readers of Regeneration as the young man who had landed face-first in a rotting German corpse. His symptoms only eased when he sought solace in the countryside. Rivers felt that his experience had been so terrible that he could not recommend attempting to overcome its suppression.

The final case was an example of chronic PTSD', in which the sufferer's means of coping with his experiences have become part of the problem. His habits of avoidance had become so entrenched that they were difficult to break, and Rtvers's gentle encouragement to "read the papers, talk occasionally about the war, and gradually accustom himself to thinking of, and hearing about, war experience" met with only limited success. He cites this case "as an example of the state produced by long continued repression, and of the difficulties which arise when the repression has had such apparent success as to make the patient believe in it".

A more general discussion of the processes involved in the formation of symptoms and their treatment is then given. Dissociation was considered by Rivers to be central to the development of post-traumatic symptoms, as indeed it still is. He makes an important link between the memories of war experiences and their associated affect - the sufferer must not only work through the repressed memories but also re-experience the associated emotions in order to integrate them into his personality and make sense of them. Rtvers also considers how this treatment may have caused change in his patients. Both the reintegration of repressed experiences and simple methods of education are felt to be important. and the extent to which his own faith in the treatment may have influenced its success is not discounted.

The picture of Rivers which emerges is that of a diffident, sensible and humane man, combining intuition and rationality in his attempts to find the most effective ways to treat his patients. The mixture of pragmatism, detailed clinical description and scientific rigour exemplifies the British psychiatric tradition at its best. His therapeutic techniques, together with his collaborative approach, the emphasis on current symptoms and the brief duration of therapy. have more in common with modern cognitive approaches then with either the mainstream psychiatry of his day or Freudian psychoanalysis. No wonder this complex man should have so interested Pat Barker that she took his work as the starting point for her sequence of novels and indeed made him a central figure in it.

\section{Note}

W. H. R. Rivers had many other interests apart from the treatment of war casualties. He was a Fellow of the Royal Society, first president of the Medical Section of the British Psychological Society, and helped to set up the department of Experimental Psychology at Cambridge. He was a noted anthropologist, and is also known for his experiments on nerve conduction and for his writings on psychoanalysis. An affectionate description of him is given in the other major trilogy about the First World War, Siegfiried Sassoon's three volumes of memoirs.

Pat Barker's novels are published by Viking. The first two are available as Penguin paperbacks.

\section{Reference \\ LANCET (1918) An address on the repression of war experience. Lancet. Feb. 2nd, 173-177.}

Peter Howorth, Registrar in Psychiatry, formerly at the Regional Alcohol and Drug Service, Plummer Court, Carliol Place, Newcastle upon Tyne NE1 6UR 